\title{
PHOTOGRAMMETRIC TECHNIQUES FOR PROMOTION OF ARCHAEOLOGICAL HERITAGE: THE ARCHAEOLOGICAL MUSEUM OF PARMA (ITALY)
}

\author{
E. Dall’Asta ${ }^{*}$, N. Bruno ${ }^{\text {a }}$, G. Bigliardi ${ }^{\mathrm{b}}$, A. Zerbi ${ }^{\mathrm{a}}$, R. Roncella ${ }^{\mathrm{a}}$ \\ ${ }^{a}$ Università degli Studi di Parma, Dipartimento di Ingegneria Civile, dell'Ambiente, del Territorio e Architettura, Parco Area delle \\ Scienze 181A, 43124, Parma, Italy - (elisa.dallasta, nazarena.bruno)@studenti.unipr.it, (riccardo.roncella, andrea.zerbi)@unipr.it \\ b 3D ArcheoLab, Via Naviglio Alto 4/1, Parma, Italy - bigliardi@3d-archeolab.it
}

Commission V, WG V/2

KEY WORDS: Cultural Heritage, Photogrammetry, 3D reconstruction, Augmented Reality, Cultural Divulgation

\begin{abstract}
:
In a context rich in history and cultural heritage, such as the Italian one, promotion and enhancement of historical evidences are crucial. The paper describes the case study of the Archaeological Museum of Parma, which, for the main part, conserves evidences found in the roman archaeological site of Veleia (Piacenza, Italy). To enhance the comprehension of the past, the project aims to promote the exhibits through new digital contents, in particular 3D models and AR applications, to improve their usability by the public. Projects like this pose some difficulties especially in data acquisition and restitution due to complexity of the objects and their dimension and position that are not always adequate for an easy survey. Furthermore, in this case, it was necessary to find a solution that takes into account, on one hand, the necessity of a high degree of detail to ensure high metric quality and, on the other hand, the need of producing small files, in order to easy load and consult them on the web or smartphone applications. For all these reasons, close-range photogrammetry was considered the most adequate technique to produce the major part of the models. In this paper, particular attention will be dedicated to the description of the survey campaign and data processing, underlining difficulties and adopted solutions, in order to provide a methodological summary of the actions performed.
\end{abstract}

\section{INTRODUCTION}

Museum items and small relics, as well as cultural landscapes, from historic buildings and ancient monuments to city centres and archaeological sites, are testimony of past human activities. Cultural Heritage $(\mathrm{CH})$ objects exhibit great variety in their nature, size and complexity and, therefore, a wide suite of activities, which include assets survey, restoration, conservation and monitoring, together with textual and other information collecting, have to be considered for achieving an accurate cultural documentation. This represents a major issue for the present and future society: culture and heritage play a vital role in individual and community development, providing cultural, aesthetic and spiritual satisfaction.

The importance of cultural and natural heritage documentation is well recognized at international level, and there is an increasing pressure to its application to the wider extent possible. A correct and significant documentation is sought as the primary factor for allowing an efficient cultural heritage communication as well. The idea of creating an international movement for protecting heritage emerged after World War I. During the 19th and 20th centuries archaeological excavations became common and appealing practices. Over recent decades, international agencies have passed resolutions concerning the obligation for protection, conservation and restoration of monuments. They identified guidelines for conservation works, management, appraisal, assessment of the structural condition, archiving, publication and research purposes. In this regard, UNESCO (1945) and the Council of Europe have formed specialized organizations for conservation of cultural heritages. ICOMOS (International Council for Monuments and Sites) is the most important one, but also CIPA (International Committee for Architectural Photogrammetry), ISPRS (International Society for
Photogrammetry \& Remote Sensing), ICOM (International Council for Museums), ICCROM (International Centre for the Conservation and Restoration of Monuments) and UIA (International Union of Architects) are all involved in conservation task of cultural heritages (Georgopoulos and Ioannidis, 2004).

Up to present, several and important developments have been achieved with regard to survey, restoration and conservation technologies: new sensors and data acquisition methodologies, new 3D representations, new data visualization and interaction platforms, together with the improvement of existing ones, are constantly leading heritage documentation and preservation in the digital environment. At the same time, new way of communication, such as digital web content (E-Curator project, 2016; 3D Virtual Museum project, 2016), Augmented Reality (AR) (Wojciechowski, et. el., 2004; Zoellner, et. al., 2009), digital installation and video projection (Basballe, et. al., 2010), provides new opportunities and attracts a wider (and probably younger) audience. In this regard, photogrammetry can be considered an optimal survey technique in a wide variety of archaeological and architectural contexts, being able of coping with different objects complexity, quality and metric accuracy requirements, low time and budget limitations and easy usage of the final products. Being the photogrammetric equipment in many cases cheap and already available to most of the people, and thanks to the ever growing availability of freeware Structure from Motion (SfM) and Dense Matching software packages (OpenCV library; 2016; Pierrot Deseilligny, et. al., 2011; Snavely et al., 2006), which automates most of the photogrammetric pipelines, the technology is also very useful for promoting crowdsourced documentation campaign.

The paper describes the first stages of a promotion project of the 
Archaeological Museum of Parma (Italy), where evidences of the near roman archaeological site of Veleia (Piacenza, Italy) are conserved. There is a separation between the site of discovery and the place of preservation (ca. $50 \mathrm{~km}$ ), which forces the exhibits in a framework different from the original one and limits the visitor comprehension of the original context. The project, entitled "Innovative multimedia exhibitions itinerary for the promotion of the Archaeological Museum of Parma" aims to integrate and connect the historical and cultural sites (the archeologic area and museum ones), promoting the documentation and interconnection of the assets and developing a virtual connection with the Veleia site. Among these, some of the most interesting Veleia finds, exhibited in the Archaeological Museum of Parma, are: the Giulio-Claudio statuary, composed of twelve honorary marble sculptures symbolizing the imperial family members, which was located along the back wall of the original Veleia basilica; the Tabula Alimentaria, a bronze inscription showing rules of the Trajan Emperor and several antique bronzes and historical-cadastral maps.

The aim of the project is to promote the museum cultural assets through new digital contents (reality-based 3D models of heritage sites and objects, AR applications) for improving the information level and offering a "journey" to the past by way of a virtual experience that takes the individual in the original ancient Roman forum of Veleia. At the same time, the possibility of producing 3D models of some assets by means of 3D prints will also allow creating sensorial itinerary for disabled users. The expected activities involve the University of Parma for the digital technical contents creation, together with the support of the National Archeological Museum of Parma (and of the Archology Authority of Emilia Romagna) for the set-up, integration and management activities of the multimedia contents and the events linked to the usage and promotion of the heritage of the museum.

\subsection{Related work on the topic}

To enrich the visibility of their exhibits, nowadays, several museums worldwide have invested consistent efforts improving their ways of communication and providing innovative methods for the divulgation of contents (White, et. al., 2004; 3D Virtual Museum Project; Hall, et. al., 2001; Wojciechowski, et. al., 2004). Virtual museums, smartphone and tablet applications, augmented reality, etc. are today widespread. These technologies are progressively becoming usable by a large number of people. Projects of crowdsourcing, in which users can produce contents themselves, are common too (Oomen, et. al., 2011). However, when these data are devoted to archaeological or scientific studies, their accuracy is essential and becomes fundamental to provide metrological reliability of the data, which requires specific know-how. In this regard, we must address the issue, taking into account different usage levels/purposes of the surveyed content. On one hand, we must emphasize the aesthetic qualities of the final product which has to be appealing and, at the same time, easily accessible and usable by the public (small files with light data volumes). This can be assured producing realistic 3D textured models easy to load and consult on web or smartphone applications, which can provide free user interaction for education, entertainment, or tourism applications. On the other hand, the metric quality and accuracy of the digital surface models (DSMs) becomes essential for guarantying the reliability of the data acquisition method and ensuring a high degree of detail for research and documentation purposes.

3D modeling is currently one of the most active research area in photogrammetry, computer vision and graphic fields (Remondino, 2011): three-dimensional digital models are essential elements in many applications such as closerange/archaeological survey, entertainment, navigation and automated systems, object identification, visualisation and animation. Recently it has become a very important and fundamental activity in particular for $\mathrm{CH}$ digital archiving making possible the documentation of damaged and notaccessible assets, interaction without risk of damage, development of museums virtual tourism and new educational experiences. This requires a wide suite of activities that include surveying, high-accurate and photo-realistic 3D modelling (i.e. multi-source, multi-format and multi-content information, with stated levels of accuracy and detail) since the geometry of the object is not the only parameter to be recorded (D'Ayala and Smars, 2003). Moreover, scientific and historical-archaeological research should also take care, in many cases, of budget limitation, portability and flexibility of the modelling technique and, finally, it has to assure a user-friendly way for information visualization and dissemination. Selecting the most appropriate 3D modelling technique to satisfy all these requirements is not an easy task (Remondino, 2006): many contributions have been dedicated to review and compare various acquisition systems (Grussenmeyer, 2006; Remondino, 2011) and to classify surface reconstruction and measurement techniques (Remondino, 2006). There is no universal terrestrial laser scanner system that can achieve all documentation applications; however, in cultural heritage documentation, the most used and useful instruments are those based on the optical triangulation method (Fontana, 2006). Triangulation scanner systems can perform the measurement up to a few meters and assure a few micrometers acquisition accuracy. However, these instruments are expensive and their use cannot be assured in all the survey conditions. Although nowadays terrestrial laser scanning systems are very popular for cultural heritage documentation and 3D modeling, photogrammetry still remains an optimal solution for achieving accurate results and complete products in all possible operational frameworks.

Many problems must be evaluated when museum assets have to be surveyed. Immovable objects can generate problems for data acquisition: objects dimension and position are not always adequate for an easy survey. Surface complexity, high and rapid depth changing, material reflectance and lighting conditions can cause problems in the acquisition and 3D models production and can lead to erroneous surface reconstruction.

\subsection{The case study: problems and limitations}

Specifically addressing the Veleia heritage exhibits in the Archaeological Museum of Parma, several problems, made the data acquisition difficult. As it is shown in Figure 1, the important marble statuary symbolizing the Giulio-Claudio family, which represents the hearth of the remaining Veleia cultural and artistic heritage, is exhibited in a specific room where the sculptures are placed sequentially and, unfortunately, adjacent to the perimetral walls. Taking into account the very small space between the sculptures body and the back wall, and the impossibility of moving the artifacts, the data acquisition has just been possible by using a digital camera with wide-angle optics.

The sculptures draperies complexity offers an undeniable aesthetic beauty play, but the sudden depth changes that characterize the dresses require a high-accurate and detailed photogrammetric survey. A high-coverage between digital images, as well as a good design of the image block, must be guaranteed in order to model the finer details of the objects body and drapery. Materials reflectance and lighting conditions can cause difficulties. For avoiding shadows areas on the investigated artefact, artificial light sources, moved and placed around the object, must be used. The use of directional light source, together with the reflecting power of marble and, in particular, bronze materials (see for instance Figure 2), are key issues that must be 
taken into account for obtaining a successful, complete and accurate survey and 3D modelling.

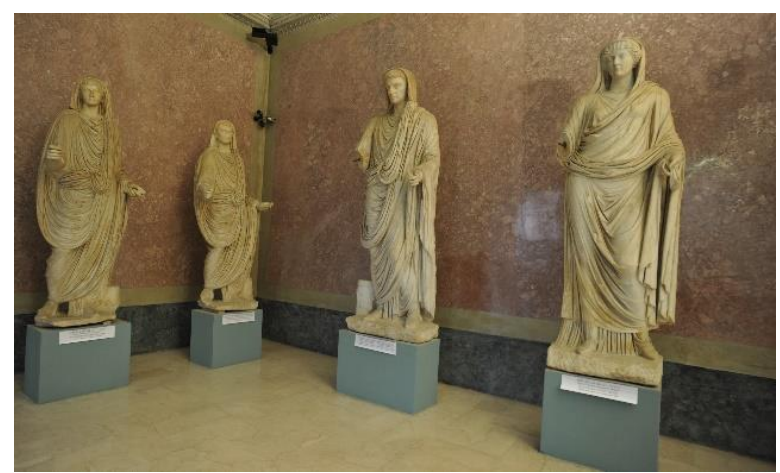

Figure 1. The Giulio-Claudio statuary exhibited in the Archaeological Museum of Parma.

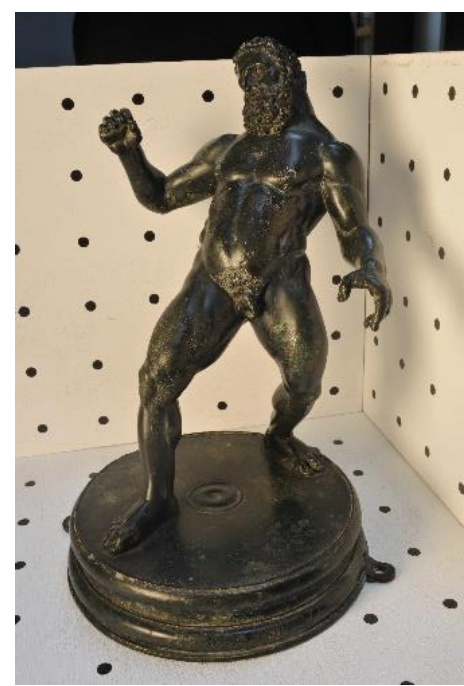

Figure 2. One of the antique decorated bronze exhibited in the Museum of Parma: the Drunken Hercules ("Ercole Ebbro") statuette case.

The paper will deal with the description of the photogrammetric survey campaigns and data processing pipeline, underlining the encountered difficulties and the adopted solutions. Finally, a metric evaluation of the $3 \mathrm{D}$ reconstructed data will be presented.

\section{DOCUMENTATION OF THE ARCHEOLOGICAL SITE OF VELEIA}

Veleia discovery occurred by chance in 1747 with the discovery of the Tabula Alimentaria, an imposing rectangular bronze plate of 136/138 x $284 / 285.5 \times 0.8 \mathrm{~cm}$, representing a partial register of croplands and pasture areas, the Veleia administrative, economic, registrar and topographical Breviarium as well as the public register and the account book of the found fifth one land mortgages (Criniti, 2014).

The excavations were performed in several campaigns (Riccomini, 2005) and, in a discontinuously manner, it were protracted until the first decades of the ' 900 . Until now, the bore, the thermal baths, the basilica, a cistern for water collection (castellum aquae) and some areas of the residential district (Figure 3) (Criniti, 2014) were uncovered and restored.

As already pointed out, there is a separation between the site of discovery of the Veleia finds and the place of conservation and exhibition, which made necessary a better of a link between the two sites. The aim is favouring and improving the level of knowledge and usability about the story of the roman archaeological site and highlighting how the Veleia discovery has been a time of change and renovation in the history of Parma and its cultural and artistic heritage. To this aim, it was decided to build a GIS (Geographic Information System) on the archaeological site, which allows promoting toward the public the consultation and comprehension of several documents and information such as orthophotos and digital terrain models of the site, historical maps connected with the $3 \mathrm{D}$ reconstruction of the excavations finds actually kept in the archaeological museum.

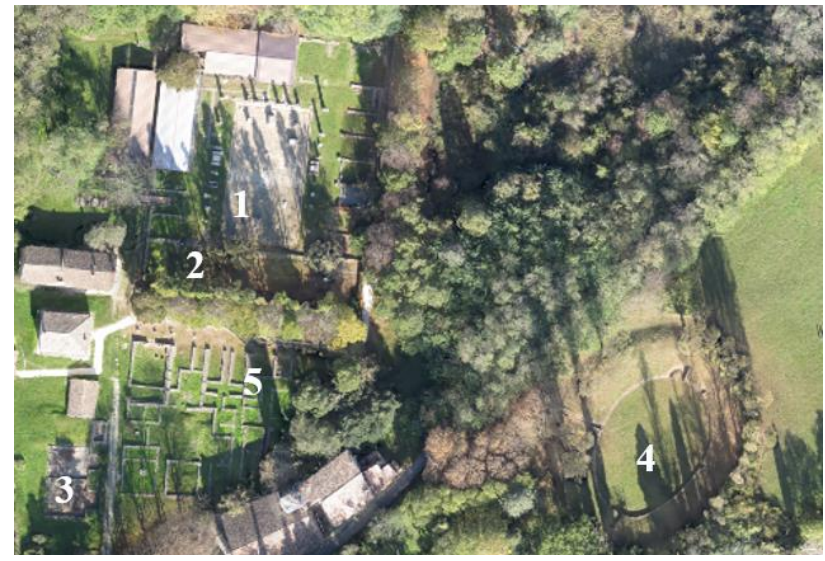

Figure 3. The overall extension surrounded by vegetation of the Veleia archaeological site: 1- the bore; 2- the Basilica; 3the thermal baths; 4 - the cistern; 5 - the residential district.

\subsection{Data acquisition}

The literature and archival research has highlighted the diversity of the data shown in the historical and / or excavation maps, as well as the lack of an accurate and updated cartography. For these reasons, the first requirement was to provide a cartographic base map for reconstructing the current state of the site.

A wide survey campaign, with the use of different techniques, was designed and carried out: a topographic network, realized using total-stations (Topcon IS203) and GNSS (Global Navigation Satellite System) data acquisition systems (Leica 1230 and SR500) provided the support both for the realization of detail surveys and of the Ground Control Point (GCP

At a later time, during the winter period, an aerial photogrammetric survey was performed with the use of two different UAS platforms: the EasyFly hexacopter of Eurodrone and the single wing SenseFLY Swinglet CAM. The characteristics of the two types of aircraft make them suitable to be used for different purposes: the EasyFly, having a payload of about $1 \mathrm{~kg}$, allows the use of qualitatively superior camera/optics (Samsung NX1000 equipped with a 20.3 Mpixel sensor resolution and $16 \mathrm{~mm}$ optics) and is more suitable for performing a detailed survey of the forum, basilica and cisterna area. To obtain a total overview of the site and its surrounding (an area of ca. $1 \mathrm{~km}^{2}$ ), the fixed-wing SenseFly, equipped with a Canon IXUS 125 HS (16 Mpixel sensor resolution and a $4.3 \mathrm{~mm}$ optics) and Canon PowerShot ELPH 110 HS (24 Mpixel e $4.3 \mathrm{~mm}$ optics) cameras, was considered more suitable to quickly detect extended areas over a wide range of flight altitudes.

Overall, four flights were done (a summary of the flights characteristics is presented in Table 1), including one, performed at $50 \mathrm{~m}$ altitude, with the hexacopter platform, and the remaining three with the fixed-wing UAS, realized at $130 \mathrm{~m}$, both with RGB (Red Blue Green) and NIR (Near Infra Red) cameras, and $230 \mathrm{~m}$ with just the NIR camera. 


\begin{tabular}{c|cccccc|} 
UAS & Flight & Camera & $\begin{array}{c}\mathbf{f} \\
(\mathbf{m m})\end{array}$ & $\begin{array}{c}\mathbf{Z} \\
(\mathbf{m})\end{array}$ & $\mathbf{Z / c}$ & $\begin{array}{c}\text { GSD } \\
(\mathbf{m} / \mathbf{p i x})\end{array}$ \\
\hline Hexacopter & $\mathbf{1}$ & Samsung & RGB & 16 & 50 & 0.003 \\
EASYFLY & $\mathbf{2}$ & IXUS & RGB & 4.3 & 130 & 0.030 \\
\cline { 2 - 7 } $\begin{array}{c}\text { Fixed-wing } \\
\text { Swinglet } \\
\text { CAM }\end{array}$ & $\mathbf{3}$ & ELPH & NIR & 4.3 & 130 & 0.030 \\
& $\mathbf{4}$ & ELPH & NIR & 4.3 & 230 & 0.053 \\
\cline { 2 - 7 }
\end{tabular}

Table 1 - Summary of the UAS flights characteristics, cameras parameters and Ground Sampling Distance (GSD).

Finally, for integrating the aerial survey, a Terrestrial Laser Scanner survey was performed with the Leica ScanStation C10. In particular, the bore and the reservoir areas were investigated.

\subsection{Data processing and photogrammetric products}

The UAS data were analysed individually in Agisoft PhotoScan following a classic processing pipeline: image blocks orientation, GCP manual identification, DSM and orthoimage generation. The interior orientation parameters of digital cameras have been estimated for all flights with an on-the-job calibration procedure: the UAS take-off / landing operations can modify the optic structure, undoing the efforts of an accurate pre-calibration of the camera; at the same time the rigid and robust structure of the block, characterized by orthogonal strips, considerably limits unwanted correlations between orientation and distortion parameters during the self-calibration process. The accuracy of each flights orientation solution was checked in the photogrammetric software Photomodeler Scanner (PM, Photomodeler, 2016) also, with the aim of verifying the presence of possible block deformations. In fact, PM provides much more complete statistic data about the orientation process quality and robustness. Once the image block has been verified in PM (with the use of control points), the dense cloud generation has been performed in Photoscan; then, for the digital terrain models production a TIN (Triangular Irregular Network) model has been adopted.

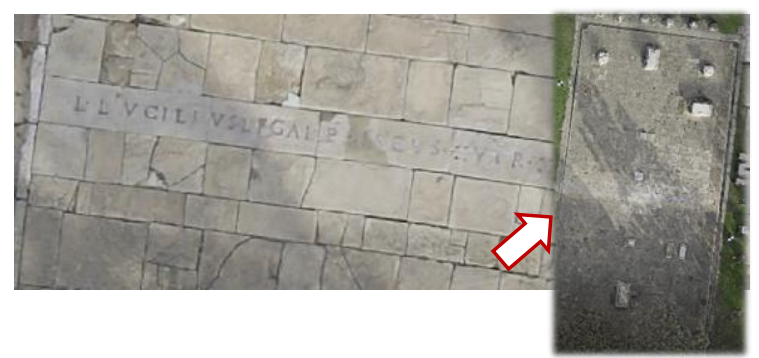

Figure $4.1 \mathrm{~cm}$ resolution orthophoto of the bore area. On the right the detail of the engraving placed on the paved floor.

Finally, with regard to the orthophotos generation step, the extension of the area and the level of resolution must be taken into account. In order to limit the data amount (in terms of memory requirement) different resolution level, as well as different portion of the whole investigated site, have been considered for the orthophotos generation. Flight 1 has allowed the generation of two orthoimages: the one depicting the whole archaeological area with $5 \mathrm{~cm}$ resolution; the second describing, with a $1 \mathrm{~cm} / \mathrm{pixel}$, the bore area (in order to define with higher detail level the silver engraving under restoration - Figure 4).

Flights 2 and 3, covering bigger areas, has allowed the generation of $10 \mathrm{~cm} /$ pixel orthophoto (the NIR product offers the advantages of allowing a better investigation of the archeologically finds with respect to the vegetation) and, finally, from Flight 4, a 20 $\mathrm{cm}$ pixel size orthophoto has been extracted.

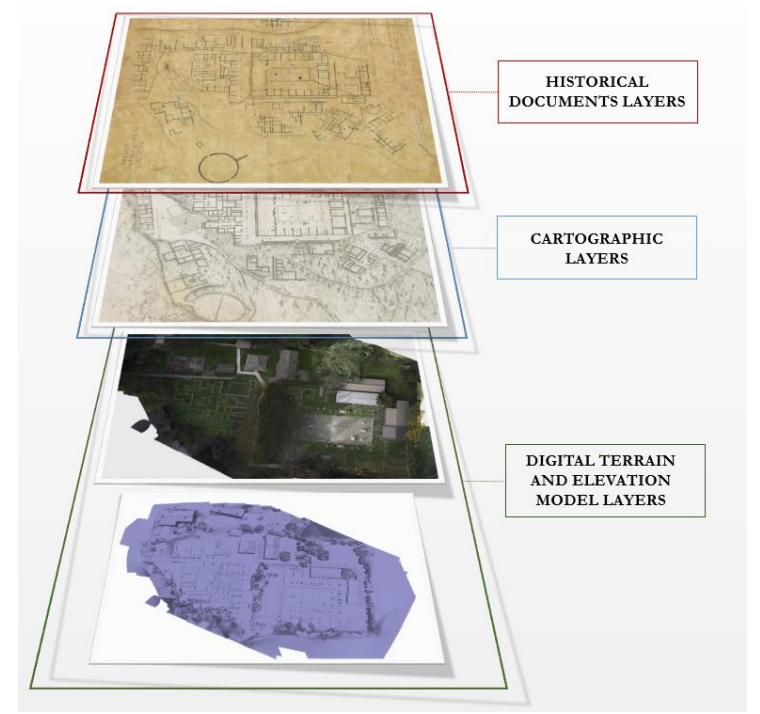

Figure 5. The structure of the Veleia GIS.

All these contents have allowed the initial structuring of the historical GIS of Veleia: data from historic plans were georeferenced using a conformal transformation by means of QGIS software, using (as fixed points) still recognizable elements on the orthophotos. Historical and cultural items provided by the plans are under vectorization together with the association of thematic data (drawing of the finds, archival documents, evidences of the excavations etc.). Orthophotos achieved from aerial photogrammetric survey provide modern thematic data. The digital terrain model layers allow describing the ground morphology and works as reference data for the definition of the current excavation heights. In Figure 5 a graphical summary of the GIS structure is presented.

The availability of the bore DSM and laser scan allow the creation of virtual 3D environment to insert the digital models of the findings in order to better illustrate the virtual link between the archaeological site and the exhibits conserved in the museum of Parma. In particular, these products can be used as backdrop to AR applications, like the creation of a virtual itinerary inside the archaeological site, as well as a travel inside the museum contents, to be allocated on Web platform and smartphone applications. These paths provide the user immersion within the Veleia site, where it is possible enjoying the archeologic site, showing not only the current state of the area but also how it (most likely) was in the past. At the time being, it is possible, for example, to display the correct location and reconstruction of the remains, like the Giulio-Claudio statuary now exhibit in the Archaeological Museum, inside the Basilica

\section{SURVEY OF THE ARCHEOLOGICAL MUSEUM EVIDENCES}

All the photogrammetric surveys have been performed using a full-format Nikon D3X $(6048 \times 4032$ pixels resolution and 6 micrometers pixel size) digital camera, with 105,35 and $18 \mathrm{~mm}$ calibrated lens.

Most of the photogrammetric operations were performed with the commercial software Agisoft Photoscan (Agisoft Photoscan, 2016), which provides a very simple and automated workflow, through the following flow-chart: (i) image orientation; (ii) highresolution dense image matching; (iii) 3D reconstruction and model texturing. A geometry or network design has been firstly studied to ensure that the number and location of the images to 
be used were appropriate to produce accurate results. To check the consistency of image orientation, all the image blocks were exported in Photomodeler and analysed more in detail.

Two different general image blocks design and workflows has been designed and tested for allowing the optimal 3D reconstruction of, respectively, the twelve sculptures that constitute the Giulio-Claudio marble statuary and the antique bronzes ("Ercole ebbro", "Vittoria alata" and "Dioniso" statuette).

\subsection{The Giulio-Claudio statuary}

The photogrammetric survey has been characterized, for each case study, by an initial image acquisition step performed on a circular geometry with a $35 \mathrm{~mm}$ focal length optic. Generally three image sequences (two for modelling the body and one for the head), taken with this geometry, have been necessary for accurate modelling all the sculpture, avoiding occlusion problems. After that, closer and shorter image sequences has been acquired for capturing sculptures particulars, such as draperies and dresses details. Finally, for acquiring images of the sculpture back side (wall adjacent) the $18 \mathrm{~mm}$ lens has been used. An example of a performed image network is shown in Figure 6.

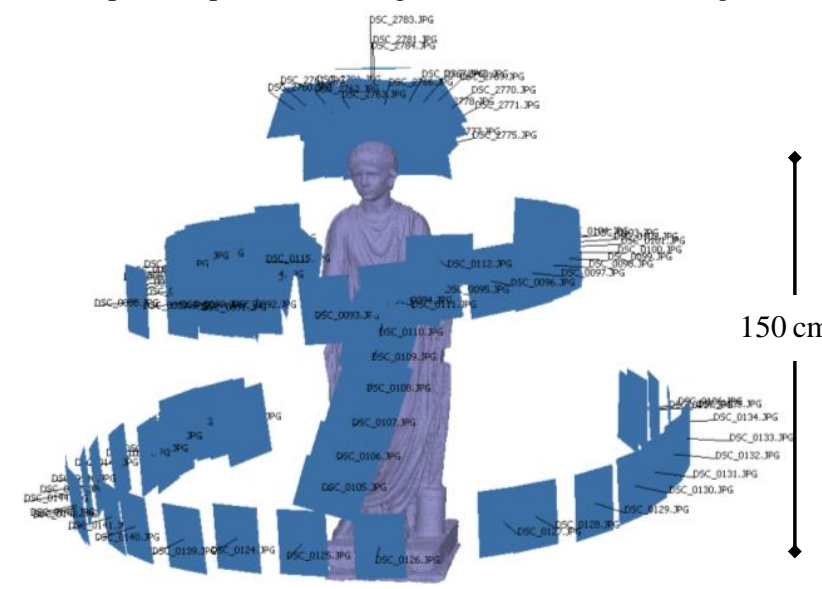

Figure 6. Typical camera network characterizing the sculptures photogrammetric surveys.

All the assets surveys were computed with the support of two artificial light sources one of which has closely followed the images acquisition geometry, generating a diffused ambient lighting in the camera acquisition direction, while the second one was used as a sidelong light source for avoiding as much as possible shadows and reflections problems. With regard to the objects back-side, since it was difficult finding an easy location for the artificial illumination (because of the reduced space between the wall and the sculpture, and the reflection problems caused by the use of too much close light sources), the lights has been kept fixed in the wall directions, in order to generate a diffuse reflected ambient illumination on the sculptures back.

The collected image sequences has been processed in Photoscan for achieving the final high-resolution three-dimensional models. The already discussed sculptures complexities, highlighted by the precense of high depth changes, reflections and discontinuity areas on the images, has made necessary the manual operator intervention for increasing the robustness of the more complex images orientation solutions.

Finally, in order to obtain control data for scaling and orient the photogrammetric reconstructed $3 \mathrm{D}$ model, and to provide a general check of reconstruction correctness, a terrestrial laser scanner Leica $\mathrm{C} 10$ has been used for computing an overview scan of the room where the statuary are exhibited. The Scanner has a nominal precision of $2 \mathrm{~mm}$, which not indicated for precise assessment of DSM accuracies at this scale; a close-range Triangulation-based Laser Scanner would be more appropriate for those tasks, but strong time-limits requirements for data acquisition (the hall must be closed to the public during the survey), discuraged its use. On the contrary, the $\mathrm{C} 10$ precision was considered appropriate in providing a good control of the block orientation, if a good amount of GCP (Ground Control Points) is used, and sufficient to highlight possible image block deformations.

Once the 3D models has been generated, a post-processing pipeline has been performed in the $3 \mathrm{D}$ modelling software Blender (Blender, 2016). However, high-resolution DSMs are not suitable for on-line consultation activities, AR reality and web/smartphone applications. Moreover, interesting studies about the sculpture level of damage and the original colour of the draperies have encouraged and motivated the data processing and manipulation in a 3D modelling enviroment.

The first processing level performed in Bleder has been the sculpture 3D model resampling for achieving a low-resolution trangulated model characterized by ca. 200 ' $000 \div 300$ '000 faces. Hole-filling and noise-reduction post-processing procedure has been performed, as well, documenting carefully where the original surveyed model has been modified. Finally, high quality texture mapping of the sculptures has been generated for creating realistic 3D models (Figure 7 shows some 3D models of the statuary).

Although many acquisition systems (e.g. laser scanner) as well as photogrammetric data processing softwares are able to capture the DSM vertex colour and also to perform model texturing (i.e. the texture is acquired from the images used for object surface reconstruction), several disadvantages can affect the final texture output. Images can show illumination and contrast problems, in
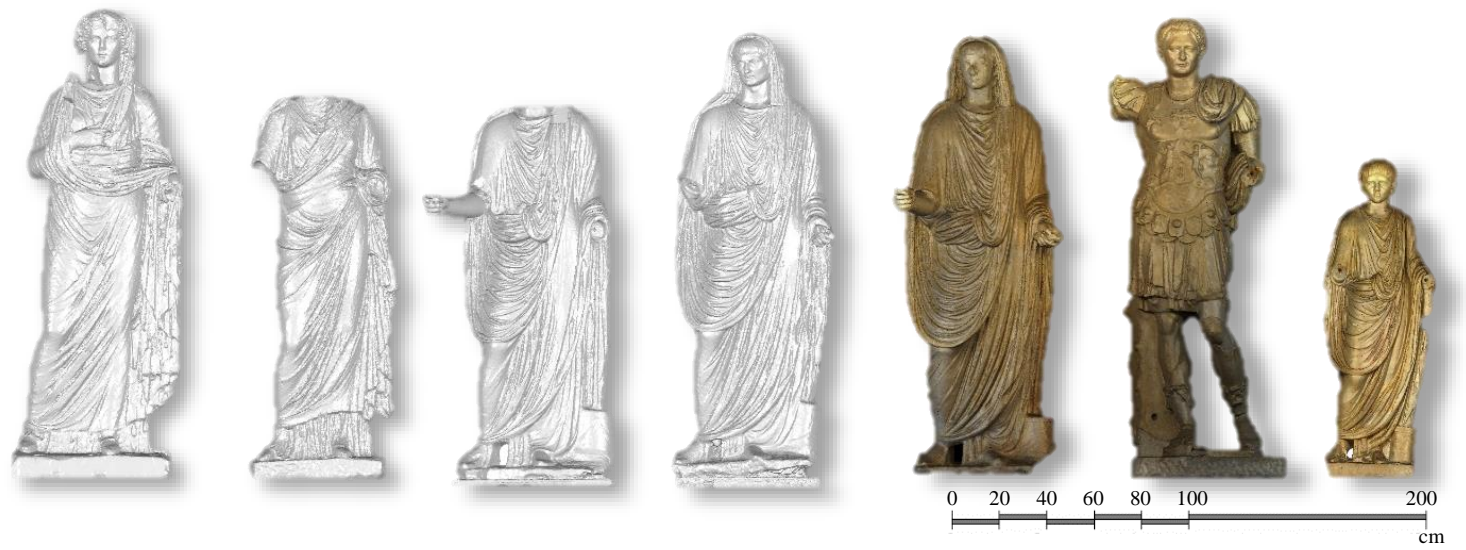

Figure 7. 3D models of the statuary: bare models and textured models. 
particular if artificial light are used, and over/under saturated areas can hide object details. Moreover, being known historical information about the sculpture drapery decoration and original colours, it has been possible adapting and combining such information on the models shape.

Therefore, the following post-processing pipeline has been followed in Blender for each sculpture digital model:

1. Since the high-resolution of the 3D models (i.e. the high number of mesh vertices), the DSM has been firstly sectioned identifying suitable "seams" on the mesh. This has allowed to isolate portions of the model which can be easily unwrap and projected on the texture plane;

2. The different sections of the mesh have been unwrapped following the defined seams, obtaining separated UV-maps (describing the whole model), that have been inserted into the image texture (see Figure 8);

3. Being obtained a unique image texture, where all the UVmap portions has been combined, the 3D models has been reimported in .obj format in Photoscan where, mantaining the new UV-map atlas, the texture was generated again;

4. Finally, the achieved texture has been adjusted in Photoshop: in some cases just homogenizing the radiometric property and in others (where historical information about the original colour of the sculpture drapery were available), modyfing directly the drapery data on the image texture according to the research studies.

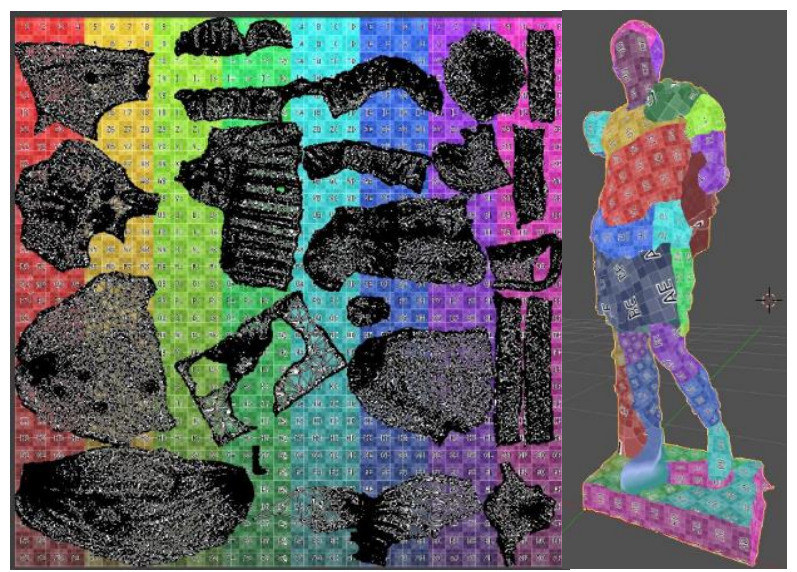

Figure 8. Blender UV-texture mapping process: on the right the 3D model and the identified seams used for subdividing the mesh; on the left the unwrapped UV-maps of each parts.

\subsection{The antique bronzes}

A different workflow characterized the antique bronzes survey. In all these case $\mathrm{s}$ the relics are much smaller, ranging from 20 $\mathrm{cm}$ to $40 \mathrm{~cm}$ in height. In this case, the high-reflectance material and the small objects details required a more careful and complex image acquisition pro cedure. Moreover, one of the antique bronzes, the "Ercole Ebbro" required a dedicated surveyed aimed at providing the highest level of accuracy possible, within the budget limitation of the project. In the following paragraph only such relic will be thoroughly described along with the motivations for such requirements, but for the other bronze statues the same approach and workflow has been/will be adopted.

3.2.1 The Ercole Ebbro survey: The Ercole Ebbro (Drunken Hercules, Inv. N. B.105(418)) is a bronze statuette found near the western porticus of the Veleia forum (Cavalieri et al., 2015). The relic (see Figure 2) represents one of the finest and most precious artifact of the Veleia collection and can be considered a work of the late Hellenistic period $\left(2^{\text {nd }}\right.$ half of the $1^{\text {st }}$ century A.D.).

Several studies and researches concerning the authenticity of the statuette were performed from the early ' 70 on, based on both stylistic and mineralogic considerations. At the same time an identical (as far as a visual comparison allows to infer) statuette, is conserved at the Civic Medieval museum of Bolougne (Italy). In this context, the researchers and scholars that work on this statuettes, are still trying to assess if one of the two are an actual replica of the other, and are trying to reconstruct the history and circumstances of th e two relics over the centuries. An accurate survey and $3 \mathrm{D}$ reconstruction of both the bronze statues was considered, at this point, strategic to evaluate actual similarity and to highlight and scientifically quantify possible discrepances. Besides the pose, shape and dimension of the relics, also a detail analysis of their surfaces, identifing matching scratches and defects for instance, can provide invaluable hints on the ordeals the statues endured during the last two thousand years. Previous survey campaign using Triangulation Laser Scanning techniques did not lead to conclusive results, being the surface highly reflective which, consequently, produced very noisy results in the final DSM. Also a photogrammetric approach, where higly reflective surfaces are considered, is a risky methodology, the most common matching algorithms relying on the same radiometric response of homologous points for identification. However, in this context, a careful design of the surveying environment, trying to limit specular highlights using cold lamps and diffuse illumination systems and polarized filters, can overcome many of (if not all) the problems (Nicolae et al., 2014). Other imaging problems should be considered in order to provide an optimal acquisition environment: above all, with this object sizes, depth of field issues should always be expected. The use of high f-numbers is not possible unless stronger illumination (which increase specular and reflection issues) is provided. Long time exposures, on the contrary, increase image noise problems. To obtain a good GSD (Ground Sampling Distance) and be able to capture the finest scratches on the statuette surface, requires the user to adopt macro long focal-length optics, staying as close as possible to the object. Finally the shape of the object, makes the depth range of some poses (think, for instance acquiring the image from the right or left hand of the Hercules) very wide.

Other consideration, involving more specific photogrammetric issues, should be taken into account as well: the most important, in authors opinion, regards the camera model calibration. Enabling the autofocus of the camera is the easiest way to provide (hopefully) good quality images, but changes in every frames all the camera's interior and distortion parameters. The use of a selfcalibration procedure assuming different parameters set for each frame, can make the Bundle Block Adjustment (BBA) unstable. On the other hand, the use of a fixed focal distance ensures the stability of the camera model parameters, but requires much longer acquisition time and efforts: it's worth noting, in fact, that the dark surface of the bronze statuette makes really hard, for the human operator, to understand if the object is focused correctly; being the focal distance fixed, the operator have to move toward/farther from the object to obtain the correct focus.

In this case we opted for a mixed approach: the object was collocated in an "acquisition box" with circular calibrated targets of known position, which was placed on a rotating tray (see Figure 2). Centering approximately the stauette on the rotation axis of the tray and fixing the camera on its trypod, makes the object-camera distance almost constant for subsequent frame acquisition. The operator starts fixing the camera focus and aquires a set of subsequent images, rotating the calibration box. Every frame is checked and, if some defocusing is detected, autofocus is enable and the frame acquired again. Then the auto-focus is deactivated and the acquisition goes on. During the image 
block orientation stage, at first an on-the-job calibration considering the same camera model for all the images acquired is performed. Analysing the BBA results, it's possible to identify if some subset of images are not consistent with the solution and should be assigned to them a different camera model: in most of the cases, considering that the change in focus is very limited and interior orientation parameters are strongly correlated with the exterior ones, especially when using long focal lengths, the split of camera models was not required.

All image blocks acquired consist of three circular strips all around the statuette, at three different heights (as showhn in Figure 9). For some details, where occlusion issues are more relevant, (for instace the upper parts of the legs and the lower part of the torso) other images have to be acquired for allowing a complete reconstruction of the model.

The software Photoscan was used to extract tie points, that were consequently reduced in number, exported in Photomodeler where the BBA was performed. The final orientation solution was exported back in Photoscan for Dense Matching and DSM reconstruction.

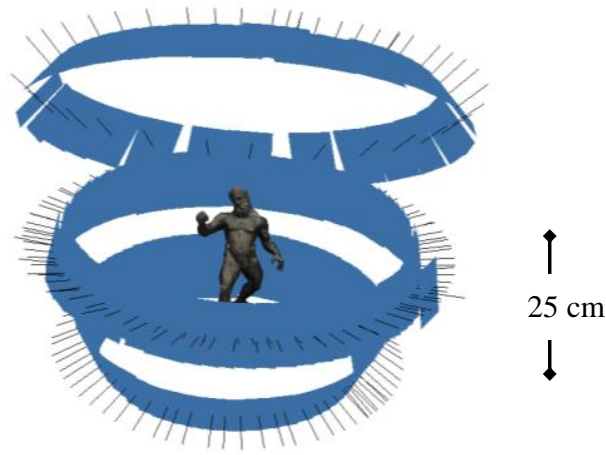

Figure 9. Image block geometry for the bronzes surveys.

To check the final accuracy of the reconstructed model a comparison with an independent technique was not possible: triangulation laser scanners does not provide good enough reference data. For this reason a repeatibility analysis was performed, comparing two different reconstructions of the object using independent subset of images. The comparison is reported in Figure 10: the results are good ans show a standard deviation value of the differences of $0.11 \mathrm{~mm}$, which is about two times the value of the calculated GSD.

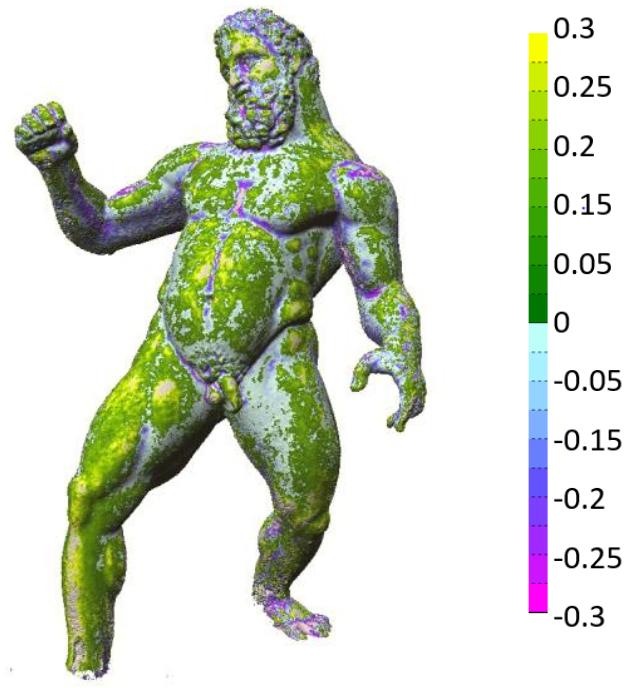

Figure 10. Comparison map [mm] between two different reconstructions of the object.
The most interesting outcomes of the comparison between the two statuettes (the Veleia and Boulogne Hercules) are reported in Figure 11 where it can be easily verified that the legs and arms poses of the two relics are quite different (with distances up to $5 \div 7 \mathrm{~mm}$ ). From the close-up images it's also quite evident that the Boulogne Hercules presents lower level of details in the beard and in the hairs. Nonetheless, a comparison of the torso of the two bronzes shows very small discrepancies (lower than 0.3 $\mathrm{mm}$ ), and some of the scratches and defects on the Veleia statue are present also on the Boulogne exemplar.
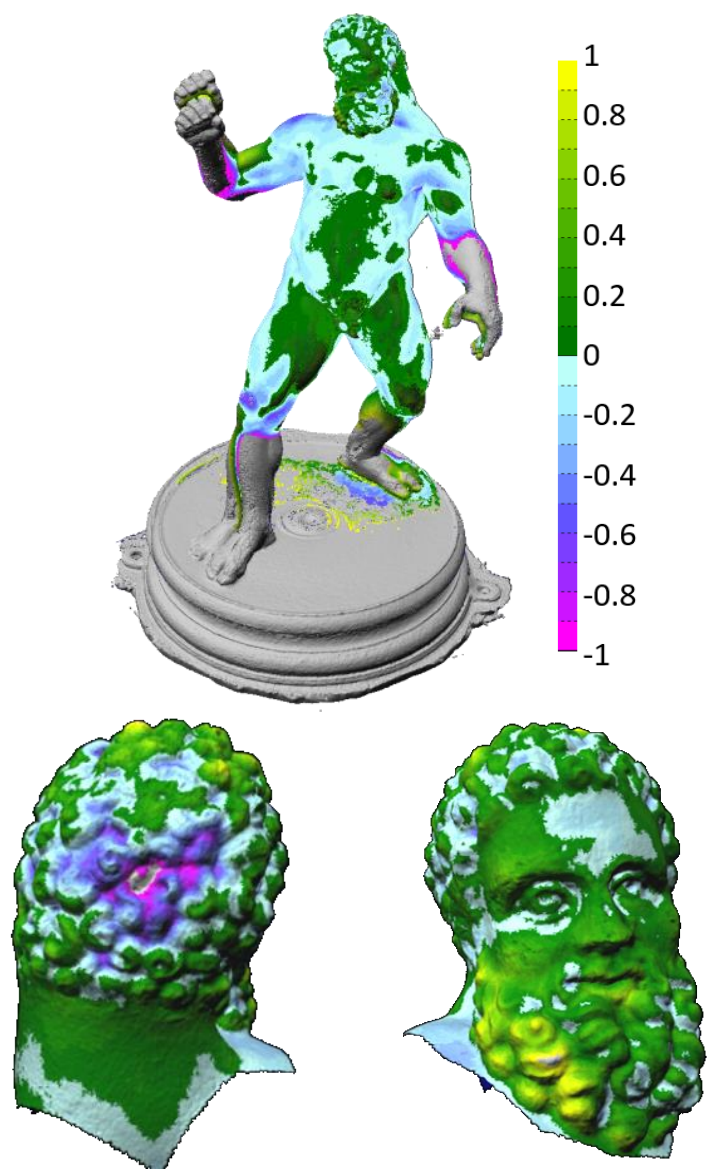

Figure 11. Comparison maps [mm] between the Veleia and Boulogne Hercules.

\section{CONCLUSIONS}

Photogrammetry represents one of the most reliable, and at the same time versatile, approach for metric (and thematic) data acquisition in cultural heritage applications. In the context of a promotional project of the National Archaeological Museum of Parma, also considering the strong budget limitation imposed, it is sought as the principal technique to provide, at low cost, 3D model reconstructions of the main roman objects kept at the museum. One of the main requirements of the project is to produce the models considering different degree of detail and accuracy in order to support both the research and documentation activities of the museum (that requires the highest level of quality) and the development of promotional content (web and smartphone applications, digital installations, AR experiences, and so on). The work is still in progress and, in this first paper, we focused our attention to the protocols and workflows designed and implemented. Although, several guidelines drawn by the principal $\mathrm{CH}$ international agencies and scientific associations, are available, every relic/case study is different and provides peculiar challenges. To ensure the documentation of such objects 
to complain with accuracy requirements is essential to provide, case by case, an adaptable workflow.

\section{ACKNOWLEDGMENTS}

This research is supported by Fondazione Cariparma within the project "Reti d'Arte 2015 - Percorsi multimediali innovative per la valorizzazione del Museo Archeologico di Parma (2015.0074)”.

\section{REFERENCES}

3D Virtual Museum Project. http://www.3d-virtualmuseum.it. Last accessed 13/04/2016.

Agisoft Photoscan. http://www.agisoft.com. Last accessed $13 / 04 / 2016$

Basballe, D. A., \& Halskov, K. (2010, November). Projections on museum exhibits: engaging visitors in the museum setting. In Proceedings of the 22nd Conference of the Computer-Human Interaction Special Interest Group of Australia on ComputerHuman Interaction (pp. 80-87). ACM.

Blender. https://www.blender.org. Last accessed 13/04/2016.

Cavalieri, M., Conversi, R., Giumlia-Mair, A., 2015. Veleia's Bronzes Collection: New Archaeological and Scientific Data and Interpretation. In New Research on Ancient Bronzes. Acta of the XVIII $^{\text {th }}$ International Congress on Ancient Bronzes. Zurich Studies in Archaeology, Vol. 10, 2015, 175-178

CIPA Heritage Documentation: Best Practices and Applications: Series 1, 2007 \& 2009: XXI International Symposium-CIPA 2007, Athens, XXII International Symposium-CIPA 2009, Kyoto. See http://www.englishheritage.org.uk/server/show/conWebDoc.4274.

Criniti, N., 2006. Il toponimo "Veleia". Ager Veleias, 1.04 (2006).

D'Ayala, D., \& Smars, P., 2003. Minimum requirement for metric use of non-metric photographic documentation. University of Bath Report.

E-Curator Project Web site http://www.museums.ucl.ac.uk/research/ecurator. Last accessed $13 / 04 / 2016$.

Fontana, R., Greco, M., Materazzi, M., Pampaloni, E., Pezzati, L., Rocchini, C., \& Scopigno, R., 2002. Three-dimensional modelling of statues: the Minerva of Arezzo. Journal of Cultural Heritage, 3(4), 325-331.

Georgopoulos, A., and Ioannidis, C., 2004. Photogrammetric and surveying methods for the geometric recording of archaeological monuments. Archaeological Surveys, FIG Working Week.

Grussenmeyer, P., Landes, T., Voegtle, T., \& Ringle, K., 2008. Comparison methods of terrestrial laser scanning, photogrammetry and tacheometry data for recording of cultural heritage buildings. ISPRS Arch. Photogramm. Remote Sens, 37 , W5.
Hall, T., Ciolfi, L., Bannon, L., Fraser, M., Benford, S., Bowers, J., ... \& Flintham, M., 2001, November. The visitor as virtual archaeologist: explorations in mixed reality technology to enhance educational and social interaction in the museum. In Proceedings of the 2001 conference on Virtual reality, archeology, and cultural heritage (pp. 91-96). ACM.

Nicolae, C., Nocerino, E., Menna, F., \& Remondino, F. (2014). Photogrammetry applied to problematic artefacts. The International Archives of Photogrammetry, Remote Sensing and Spatial Information Sciences, 40(5), 451.

Oomen, J., \& Aroyo, L. (2011, June). Crowdsourcing in the cultural heritage domain: opportunities and challenges. In Proceedings of the 5th International Conference o

OpenCV-Open Source Computer Vision Library: http://opencv.org. Last accessed 13/04/2016.

Patias, P., 2007. Cultural heritage documentation. Application of $3 D$ measurement from images, 59(3), 225-257.

Photomodeler

http://www.photomodeler.com/index.html. Last accessed $13 / 04 / 2016$.

Pierrot Deseilligny, M., \& Clery, I. (2011). Apero, An Open Source Bundle Adjusment Software For Automatic Calibration And Orientation Of Set Of Images. In IAPRS Vol. XXXVIII5/W16, Trento.

Remondino, F., \& El-Hakim, S., 2006. Image-based 3D modeling: a review.

Remondino, F., 2011. Heritage recording and 3D modeling with photogrammetry and 3D scanning. Remote Sensing, 3(6), 11041138 .

Riccomini, A. M., 2005. Scavi a Veleia: l'archeologia a Parma tra Settecento e Ottocento.

Snavely, N., Seitz, S. M., \& Szeliski, R. (2006). Photo tourism: exploring photo collections in 3D. ACM transactions on graphics (TOG), 25(3), 835-846.

White, M., Mourkoussis, N., Darcy, J., Petridis, P., Liarokapis, F., Lister, P., ... \& Stawniak, M., 2004, June. ARCO-an architecture for digitization, management and presentation of virtual exhibitions. In Computer Graphics International, 2004. Proceedings (pp. 622-625). IEEE.

Wojciechowski, R., Walczak, K., White, M., \& Cellary, W., 2004, April. Building virtual and augmented reality museum exhibitions. In Proceedings of the ninth international conference on 3D Web technology (pp. 135-144). ACM.

Zoellner, M., Keil, J., Wuest, H., \& Pletinckx, D., 2009. An augmented reality presentation system for remote cultural heritage sites. In Proceedings of the 10th International Symposium on Virtual Reality, Archaeology and Cultural Heritage VAST (pp. 112-116). 